\title{
LIFE HISTORY AND MULTIPLE ANTIPREDATOR DEFENSES OF AN INVERTEBRATE PELAGIC PREDATOR, BYTHOTREPHES LONGIMANUS
}

\author{
Dietmar Straile ${ }^{1}$ AND Astrid Hälbich \\ Limnological Institute, University of Konstanz, P.O. Box 5560, D-78457 Konstanz, Germany
}

\begin{abstract}
Multiple antipredator defense strategies and their interactions were examined in a field study of the predatory planktonic waterflea Bythotrephes longimanus in Lake Constance, at the northern fringe of the European Alps. Because of its large body size and conspicuousness, Bythotrephes is a preferred prey of freshwater fish. We observed seasonal changes in life history and morphology and diel vertical migration, all best understood as a response to fish predation. Bythotrephes population dynamics were characterized by pronounced population growth in late spring, maximum abundances in June, and a steady decline toward the end of the season. In late spring, high population growth rates were achieved by means of large clutches, low investment in individual offspring, and small size at first reproduction. While the population was still increasing, a marked life history shift occurred. The reproductive strategy of females switched toward high per-offspring allocation at the expense of clutch size. This change in reproductive behavior resulted in an increase in the size of neonates and was accompanied by an increase in the size at first reproduction. Such a life history shift is typically observed in the presence of gape-limited predators, which points to the importance of juvenile fish as the principal vertebrate planktivores in Lake Constance. The length of Bythotrephes defensive spina increased throughout the season, reflecting increasing predation pressure, probably owing to seasonally increasing mouth gape size of juvenile fish. In contrast to the predictions of the predator-avoidance theory, the migration amplitude of large and conspicuous Bythotrephes was small as compared to other zooplankton species. We argue that theory and data can be reconciled if the migration behavior of Bythotrephes is considered as a result of an interaction of predator defenses in the presence of predominantly juvenile, gape-limited fish. As Bythotrephes achieved protection because of its life history and spina, the costs of large diel migrations may outweigh the benefits.
\end{abstract}

Key words: alternative antipredator defenses; Bythotrephes; diel vertical migration; gape-limited predation; juvenile fish; Lake Constance, European Alps; life history; morphological defense; offspring allocation; reproductive investment.

\section{INTRODUCTION}

Predation is known to influence the biology of prey species in numerous respects, including their morphology (Harvell 1984, Brönmark and Miner 1992, Tollrian 1995), behavior (Lima and Dill 1990, Lampert 1993, Sih 1994), and life history traits (Crowl and Covich 1990, Wellborn 1994). The intensity of a predatorprey interaction, the direction of the selection pressure imposed on the prey population, and the suitability of a certain defensive trait depend on the type of predator (Polis 1988, Wilbur 1988, Persson et al. 1996). Nongape-limited predators (NGLPs) whose prey size windows encompass the size spectra of a prey population generally select the largest individuals of a population (Brooks and Dodson 1965, Wellborn 1994). Feasible defensive responses to NGLPs include life history shifts (Wellborn 1994, Rodd and Reznick 1997) and behavioral defenses (Lampert 1993, Endler 1995, Persson et al. 1996). The prey size window of a gape-

Manuscript received 20 July 1998; revised 23 December 1998; accepted 29 December 1998.

${ }^{1}$ E-mail: dietmar.straile@uni-konstanz.de limited predator (GLP) does not include the large individuals of a prey population (Huangh and Sih 1991, Wellborn 1994). In response to GLPs' life history shifts (Crowl and Covich 1990, Tollrian 1995), behavioral defenses (Kvam and Cleiven 1995) and morphological defenses are common (Stemberger and Gilbert 1987, Wicklow 1988, Brönmark and Miner 1992, Tollrian 1995). Some species are known to exhibit several defensive traits. For example, daphnids may react to increased predation pressure with life history shifts (Taylor and Gabriel 1992, Tollrian 1995) and changes in behavior (Lampert 1993, Kvam and Cleiven 1995) and morphology (Tollrian 1995, Swaffar and O'Brien 1996). Likewise, increased predation pressure on guppies is associated with changes in life history, behavior, body form, and color (Endler 1995). While the predation effect on individual defensive traits is well studied, relatively little is known concerning the effects of predation on the interactions between different traits (Sparkes 1996, De Meester et al. 1995).

The freshwater onychopod cladoceran genus Bythotrephes longimanus (Cladocera, Cercopagidae) is na- 
tive to lakes throughout the Palearctic (Berg and Garton 1994) and reproduces parthenogenetically during the summer and gametogenically during autumn (Mordukhai-Boltovskaya 1957, Ketelaars et al. 1995). Because of its large body size, Bythotrephes is highly positively selected by adult fish, i.e., NGLPs, and thus is important if not dominant in the diet of fish in many temperate lakes, including Lake Constance (Giussani 1974, Nilsson 1974, Langeland 1978, Fitzmaurice 1979, Becker 1992). However, not adult fish but juveniles are regarded as the most important planktivorous fish in many lakes (Mehner and Winfield 1997). As mouth gape size increases with growth, juvenile fish switch progressively to larger prey items and finally start to ingest Bythotrephes around midsummer (Hartmann 1983, Jachner 1991, Wang 1994) but remain GLPs in respect to Bythotrephes (Barnhisel and Harvey 1995). Hence, Bythotrephes is exposed at the same time to GLPs and NGLPs, i.e., juvenile and adult fish. Many studies focus on the effects of a single type of predator, and relatively few have compared the effects of different types of predators on prey populations (Wilbur and Fauth 1990, Kurzava and Morin 1998, Sih et al. 1998). The exposure of prey species to different size classes, species, and types of predators is probably the norm rather than the exception (Hall and Raffaelli 1991, Polis 1991) and may have effects that cannot be predicted simply by summing the effects of single predator types (Sih et al. 1998).

The defensive repertoire of Bythotrephes consists of morphological (spina formation), behavioral (diel vertical migration [DVM]), and possibly life history defenses. The spina of Bythotrephes is a potent defense against young fish and may result in aversion to attacking Bythotrephes after several unsuccessful attempts by juvenile fish to ingest Bythotrephes (Barnhisel 1991 $a, b$ ). DVM has been observed in some lakes (Lehman 1987) but not in others (Lampert 1993, Yan and Pawson 1997). Recently, differing sizes of Bythotrephes in the Laurentian Great Lakes were attributed to a shift in life history in response to fish predation (Bilkovic and Lehman 1997). So far, no study has addressed all potential defenses within a single population of Bythotrephes, and few have examined interaction of defenses in other zooplankton species (De Meester et al. 1995). As both Bythotrephes and whitefish are native species in Lake Constance, a complex array of evolved antipredator defenses of Bythotrephes that facilitates its coexistence with NGLP and GLP can be expected. In this study we examine the population dynamics, life history, and morphological and behavioral defenses of B. longimanus in deep and large Lake Constance. We evaluate and interpret seasonal life history shifts in light of expectations derived from life history theory and discuss the trade-off between the three different types of defenses.

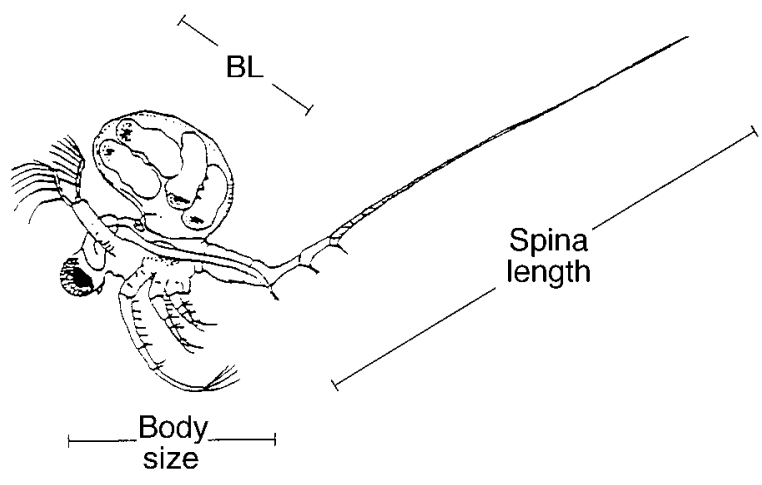

FIG. 1. Adult Bythotrephes female with three paired barbs. For each individual body size, brood sac length (BL) and spina length were measured to the nearest $0.25 \mathrm{~mm}$.

\section{Study Site And Methods}

Large $\left(472 \mathrm{~km}^{2}\right)$, deep $\left(z_{\text {mean }}=101 \mathrm{~m}\right)$ Lake Constance is situated at the northern fringe of the European Alps. Productivity and population dynamics of various planktonic taxa, as well as ecosystem properties, have been studied in great detail during the last decades (Bäuerle and Gaedke 1998). The crustacean zooplankton community consists of two Daphnia species, two Bosmina species, Eudiaptomus gracilis, three cyclopoid copepod species, and the predatory cladocerans Leptodora kindtii and Bythotrephes longimanus (Straile and Geller, 1998). The pelagic fish community is dominated by whitefish (Coregonus lavaretus).

Sampling sites for the present study were located within the northwestern part of the lake, the fjordlike Überlinger See. B. longimanus was collected with a Clarke-Bumpus Sampler (335 $\mu \mathrm{m}$ mesh size; Kahl Scientific Instrument, El Cajon, California, USA) by vertical hauls from the bottom of three sampling sites, i.e., $140 \mathrm{~m}$ (site 1), $100 \mathrm{~m}$ (site 2), and $40 \mathrm{~m}$ (site 3). Sampling was done from April until November twice a week at site 1 . Sites 2 and 3 were sampled once a week when Bythotrephes occurred in high numbers, from late June to November. If necessary, we took up to three net hauls per site and day to obtain sufficient numbers ( $\sim 100$ individuals) of Bythotrephes for reliable measurements on life history parameters and body dimensions. All samples were preserved in $4 \%$ sucrose-formalin. Profiles of water temperature and autofluorescence of chlorophyll $a$ were recorded with a combined temperature-fluorescence-turbidity sensor (Meerestechnik, Trappenkamp, Germany) and transparency by the use of a Secchi disk (30 cm diameter). Daphnids were collected at site 1 with a Clarke-Bumpus Sampler (140 $\mu \mathrm{m}$ mesh size).

From all individuals collected in each net tow, body size, spina length, and the length of the brood pouch (BL) were measured to the nearest $0.25 \mathrm{~mm}$ (Fig. 1). Because Bythotrephes shrinks in sucrose formalin during the first day of preservation (Yan and Pawson 1997), we report only length measurements done after 
this period. Age-specific morphological stages of the animals were distinguished by the number of paired barbs at the base of the spina: Neonates possess one pair of barbs, and a new pair is added at each molt (Yurista 1992). According to the number of paired barbs, we refer below to neonates (instar I), instar-II, and instar-III females. Four stages of brood development were identified: egg, embryos without pigmented eyes, embryos in the red-eye stage, and embryos in the black-eye stage. Additionally, resting eggs were distinguished. Clutch size within the egg and nonpigmented embryo stages is not easily observable, owing to the small size and inconspicuousness of eggs and embryos (Yurista 1992). Hence, we report clutch size for the red-eye and black-eye stages, and for resting eggs. The latter differ from parthenogenetic eggs in color and shell thickness (Herzig 1985) and are observable within the brood pouch.

Reproductive investment of Bythotrephes was measured using females collected in June 1998 that varied in clutch size and brood stage. They were narcotized in soda water, and their body dimensions (body size, $\mathrm{BL}$, and spina length) were measured to the nearest 0.1 $\mathrm{mm}$. Embryos were removed from the brood pouch of 37 randomly selected females. Only large unpigmented and pigmented embryos could be removed. Dry mass $(\mathrm{dm})$ of broods was determined after freezing and lyophilization of embryos (Berberovic and Pinto-Coelho 1989). From this, average embryo mass in each clutch was calculated as: average embryo mass = brood mass/ clutch size.

The vertical distribution of Bythotrephes was studied from 4 to 5 July 1996. Triplicate samples were obtained from six depth intervals $(0-5 \mathrm{~m}, 5-10 \mathrm{~m}, 10-20 \mathrm{~m}$, 20-30 m, 30-50 m, 50-140 m) with a Clarke-Bumpus sampler (335 $\mu \mathrm{m}$ mesh size) at 1200, 2030, 2400, and 0400. Animals were grouped into three categories according to their presumed susceptibility to visual planktivory, i.e., neonates, adults, and adults with brood sacks containing pigmented embryos (red-eye and black-eye stage).

The analysis of relationships between parameters sampled during a seasonal course is fraught with problems arising from autocorrelations. We addressed these problems by using two approaches. First, we analyzed relationships between various characteristics of Bythotrephes by using an ANCOVA approach, in which "date" was included as a classification variable into the set of independent variables. This allowed us to examine the relationships between various body dimensions of Bythotrephes, while holding constant any effects of seasonal changes of the dependent parameters. We did not transform data prior to these analyses, because our sample sizes were large and the central limit theorem applies (Kendall and Stuart 1977). Second, covariation in seasonal trends of variables was examined by computing Pearson correlation coefficients for averages of data at individual sampling dates. These data were logtransformed to meet assumptions of the models. For all analyses, we combined the results of all sampling sites, as no systematic differences were found in respect to the objectives of the present study. Statistical analyses were performed with SAS (SAS 1988).

\section{RESUlts}

Surface water temperatures in Lake Constance exhibited a pronounced seasonality, increasing from $4^{\circ} \mathrm{C}$ in late winter to $>20^{\circ} \mathrm{C}$ in summer (Fig. 2a). Chlorophyll $a$ concentrations increased by one order of magnitude and biomass of daphnids by three orders of magnitude during spring (Fig. 2c, d). High biomasses of daphnids resulted in a pronounced clear-water phase throughout June (Fig. 2b). Bythotrephes was absent in our samples until the beginning of May, and abundances remained low until the end of May, when the population started to increase. Maximum abundances were obtained in June and followed by a steady decline throughout the rest of the season (Fig. 3). The vast majority of individuals sampled were neonates or instar-II females. Only 50 out of $>8000$ individuals observed possessed three paired barbs. Occurrence of instar-III individuals was restricted to the time of maximum population abundance, i.e., in June (Fig. 4a). We observed $9.4 \pm 3.4 \%$ of instar-II females with pigmented embryos (red-eye and black-eye stage) at individual sampling days during summer (Fig. 4b). Very few females carrying resting eggs were observed in summer. Their contribution increased strongly from September onwards (Fig. 4b), as did the share of males (Fig. 4a).

The number of Bythotrephes offspring can only confidently be counted when embryos reach the red-eye stage. Because only $\sim 10 \%$ of the fecund females were found within this stage (Fig. 4b), the possibility for obtaining life history data for this species is restricted. To overcome this limitation, we investigated the suitability of brood sac length as a proxy variable for reproductive investment of females. Parthenogenetic young of Bythotrephes do not develop from yolk-rich eggs, as do other cladocerans. Instead, eggs are deposited into the brood sac without a shell or yolk and are nourished by fluids surrounding them (Yurista 1992). This means that reproductive investment in embryos is a continuous process, lasting from the deposition of eggs until the release of embryos, and is not already fixed at the initial deposition of eggs, as in other cladocerans. As Bythotrephes' embryos grow, they greatly expand the brood sac (Yurista 1992). Consequently, to serve as a proxy, BL should account for changes in clutch size and developmental stage of broods. BL was positively correlated with clutch size $(P<0.0001$, Fig. 5a), and it differed significantly among all developmental stages considered (TukeyKramers's procedure for multiple comparisons, all pairwise comparisons: $P<0.05$, Fig. 5b). Brood sacs with black-eye stage embryos were on average twice as large 

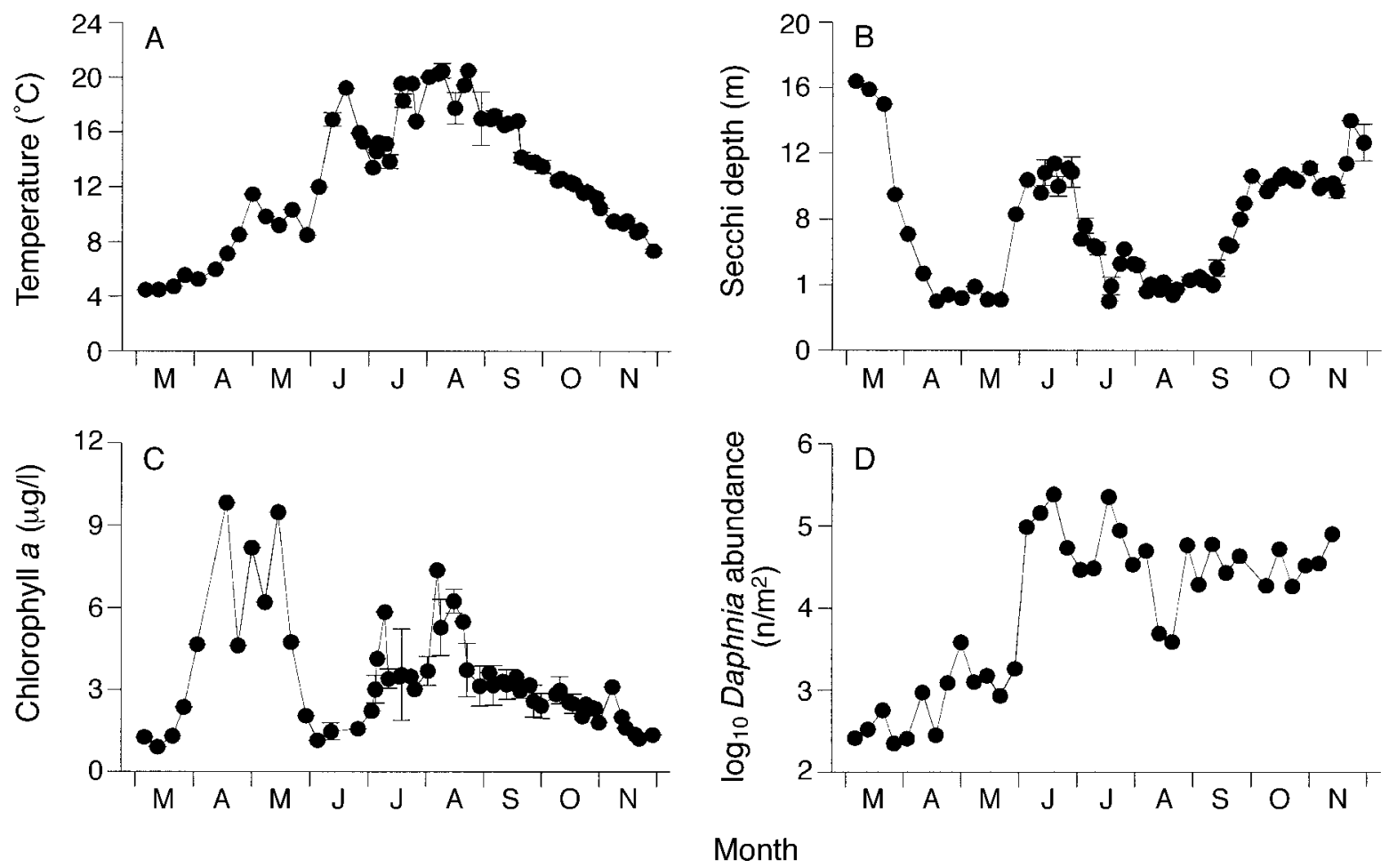

FIG. 2. Seasonal patterns (mean $\pm 1 \mathrm{SE}$ ) of (A) temperature, (B) Secchi depth, (C) chlorophyll $a$, and (D) Daphnia abundance. Temperature and chlorophyll $a$ represent average values of the upper $8 \mathrm{~m}$ of the water column. Sampling was done at site 1 during the whole study period and at sites 2 and 3 from June to November. Daphnid abundance was only recorded at site 1 .

as brood sacs with parthenogenetic eggs (Fig. 5b). As clutch size and BL exhibited strong seasonal patterns, we further analyzed the relationship between these parameters, while accounting for seasonal effects using date as a classification variable in ANCOVA. After adjusting for date, BL and brood stage were still strongly related to clutch size (Table 1a). Additionally, body size contributed significantly to the model; i.e., larger females had on average larger BL. The interaction between clutch size and brood stage did not contribute

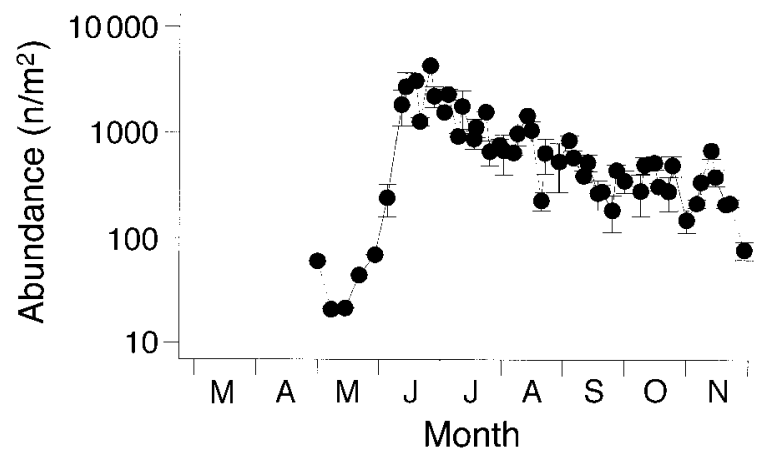

FIG. 3. Average abundance of Bythotrephes longimanus (mean $\pm 1 \mathrm{SE}$ ) during the study period. Sampling at site 1 covered the whole study period; sites 2 and site 3 were sampled additionally from June to November. significantly to the model. We repeated this analysis for a larger data set consisting of all females with brood pouches containing parthenogenetic eggs or embryos (Table 1b). Within this data set, we could not test for the effect of clutch size, because it was not observable for females with unpigmented embryos. Brood stage and body size were significantly related to BL also within this data set (Table 1b).

The suitability of BL as a proxy of reproductive investment was further confirmed by analyzing the relationship between BL and brood mass in June 1998. Brood mass increased with increasing BL (Fig. 6a, $P$ $<0.0002)$. Clutch size and brood stage were only weakly related to brood mass $(P<0.06$ and $P<0.04$, respectively) because of an inverse relationship between average embryo mass and clutch size (Pearson correlation coefficient: $r=-0.71, P<0.0001$, Fig. $6 b)$. The average dry mass of embryos from clutches $<4$ was $>200 \%$ the dry mass of embryos from large clutches.

Average clutch size decreased sharply from $>7$ at the beginning of June to 2 embryos/clutch from July onwards, and increased again in October (Fig. 7a). Average $\mathrm{BL}$ of females with pigmented embryos, but also average $\mathrm{BL}$ of females with parthenogenetic eggs and unpigmented embryos, showed a similar seasonal pattern. However, the $<50 \%$ decrease in BL during June 

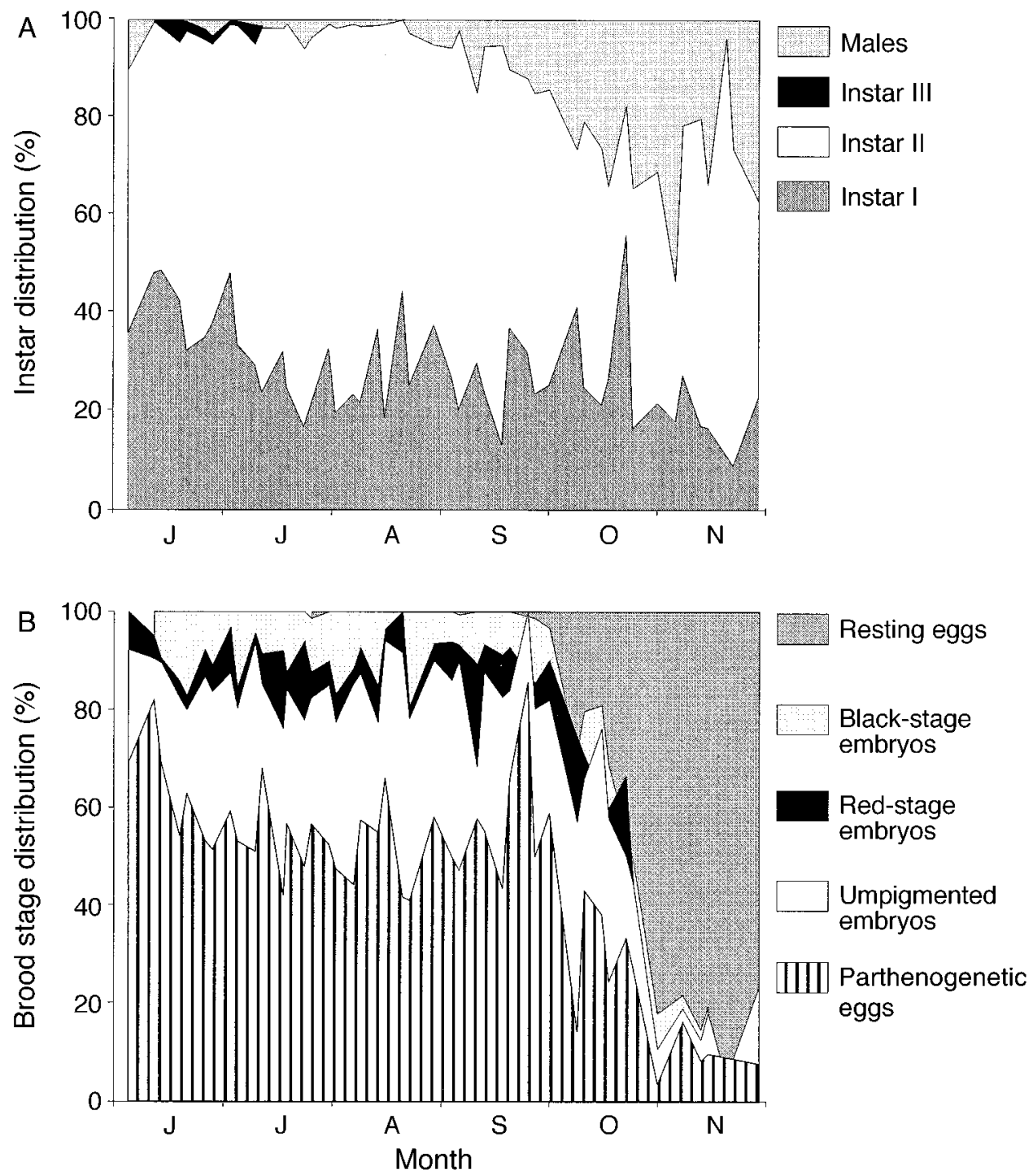

FIG. 4. (A) Relative seasonal occurrence of neonates, instar-II, and instar-III females and males. (B) Brood stage composition of adult females (instar II and instar III).

(Fig. 7b) was small compared to the $\sim 75 \%$ decrease in clutch size (Fig. 7a). Using the relationship between brood mass and BL (brood mass $=19.54+91.35 \times$ BL, Fig. 6a), we can estimate the seasonal course of brood mass from the seasonal course of the average BL of females with pigmented embryos, i.e., with embryos close to hatching. Brood mass, which is a measure of total investment in reproduction, decreased during June and the first two weeks of July but remained at a rather high level throughout the season (Fig. 8a). In contrast, average embryo mass ( = brood mass/clutch size), which is a measure of per-offspring allocation, was estimated as $\sim 20 \mu \mathrm{g} \mathrm{dm}$ at the beginning of June and increased $\sim 300 \%$ towards summer (Fig. 8b).

Average body size of neonates and instar-II females increased from low values in June towards summer (Fig. 9a, b). From July until the end of summer, neonate body size stayed constant, while the body size of instar-II females continued to increase. This resulted in an increasing difference between neonate and instarII body size (Fig. 9c, Pearson correlation coefficient: $r=0.76, P<0.0001)$. Average body size of neonates was negatively related to average clutch size (Pearson correlation coefficient: $r=-0.63, P<0.0004)$, and positively related to average embryo mass $(r=0.65$, $P<0.0002)$, which suggests that increased per-offspring allocation of females resulted in increased body size of neonates. The seasonal increase in body size of instar-II females was accompanied by an increase in the size at first reproduction, estimated as the size of the smallest female carrying pigmented embryos at the respective sampling dates (Fig. 10, Pearson correlation coefficient between size at first reproduction and date: $r=0.52, P<0.003)$. 

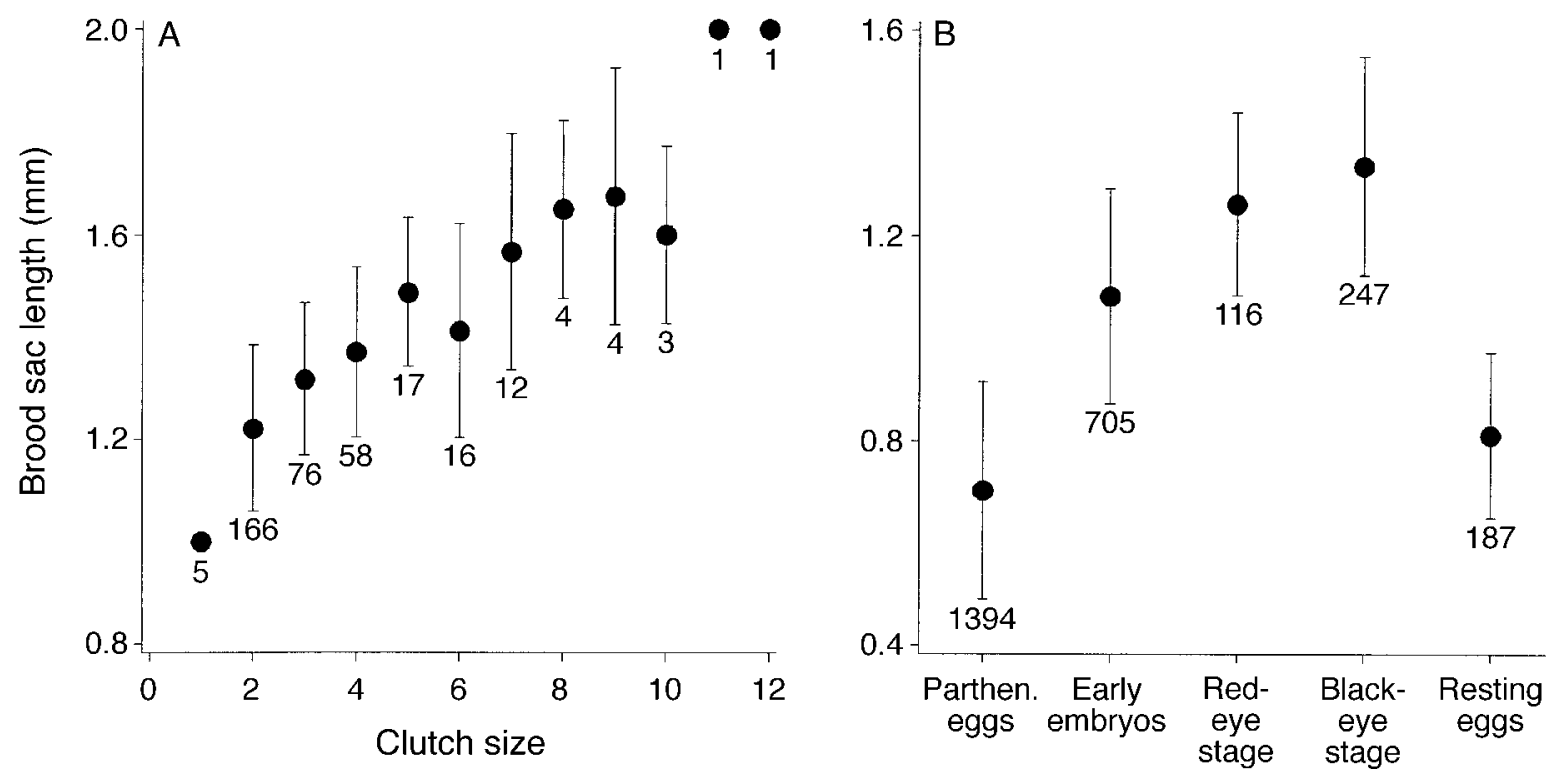

FIG. 5. Relationship of brood sac length to (A) clutch size for adults with pigmented embryos $\left(r^{2}=0.34, P<0.0001\right)$ and (B) developmental stage of offspring for all adult females with brood pouches. Vertical lines indicate \pm 1 SD. The number of measured individuals is given below each line. Brood sac length differed significantly among all developmental stages $(P$ $<0.05$, Tukey-Kramer procedure for multiple comparisons).

Body size of individual Bythotrephes was only weakly related to their spina length (Table 2). An ANCOVA with the independent variables date, instar, body size, and their interactions could only explain $27 \%$ of the variability in spina length. The significance of interaction terms suggests that the relationship between spina length and body size was not constant throughout the season and differed between instars. The slope of the spina-length/body-size relationship was positive

TABLE 1. ANCOVA for effects of date, brood stage, clutch size, and body size on BL. (a) For females with pigmented embryos, clutch size was determined and was included in the set of independent parameters. The interaction between clutch size and brood stage did not contribute significantly to the model and was removed. (b) For all reproductive females, clutch size was not always determinable and hence could not serve as an independent parameter in this model.

\begin{tabular}{|c|c|c|c|c|}
\hline Source & df & Type III ss & $F$ & $P$ \\
\hline \multicolumn{5}{|c|}{ a) Females with pigmented embryos } \\
\hline Date & 26 & 0.901 & 1.43 & 0.0816 \\
\hline Brood stage & 1 & 0.152 & 6.28 & 0.0127 \\
\hline Clutch size & 1 & 0.896 & 37.08 & 0.0001 \\
\hline Body size & 1 & 0.941 & 38.92 & 0.0001 \\
\hline \multicolumn{5}{|c|}{$\begin{array}{l}\text { Error degrees of freedom }=333 \\
\text { Error sum of squares }=8.05 \\
r^{2}=0.47\end{array}$} \\
\hline \multicolumn{5}{|c|}{ b) All reproductive females } \\
\hline Date & 34 & 32.92 & 33.07 & 0.0001 \\
\hline Brood stage & 3 & 115.34 & 1313.13 & 0.0001 \\
\hline Body size & 1 & 11.78 & 402.33 & 0.0001 \\
\hline \multicolumn{5}{|c|}{$\begin{array}{l}\text { Error degrees of freedom }=2422 \\
\text { Error sum of squares }=70.9 \\
r^{2}=0.71\end{array}$} \\
\hline
\end{tabular}

and highly significant for the first two sampling dates in June $(P<0.001)$ and was not different or only slightly different from zero during the rest of June and in July (Fig. 11). From August onwards, we again found positive relationships between the two variables. Spina length of neonates increased strongly during June from $4.5 \mathrm{~mm}$ to $>5 \mathrm{~mm}$ and remained at this level until the end of October (Fig. 12a). Average spina length of instar-II females showed a steady increase throughout the season (Fig. 12b). The difference in average spina length between neonates and instar-II females increased continuously (Fig. 12c, Pearson correlation coefficient between difference in average spina length and date: $r=0.49, P<0.0035)$. During June and July, the difference in spina length was small, but from August onwards instar-II females had larger spines than neonates.

Average spina length of both neonates and instar-II females was related to average body size of neonates and instar-II females (Pearson correlation coefficients: $r=0.50, P<0.0025$ and $r=0.70, P<0.0001$, respectively). However, the increase in spina length was partially independent from the increase in body size. For example, spina length of instar-II females with a body length of $1.8 \mathrm{~mm}$ increased from an average of $5 \mathrm{~mm}$ in June to an average of $5.4 \mathrm{~mm}$ in October.

The vertical distribution of Bythotrephes was studied for neonates, females carrying eggs or embryos with unpigmented eyes, and females carrying embryos with pigmented eyes. During the night all three groups stayed within the upper $20 \mathrm{~m}$ (Fig. 13). During the day they migrated to deeper water layers. This migration 

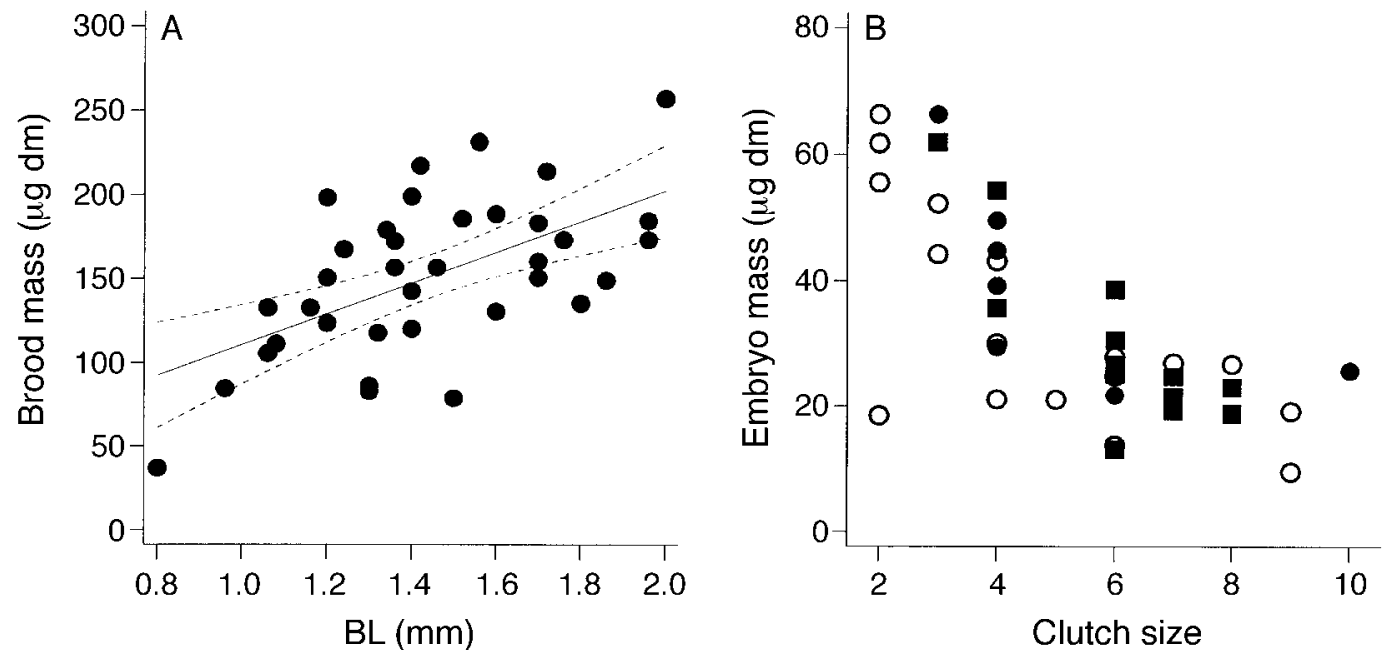

FIG. 6. (A) Relationship between brood mass and brood sac length (BL) in June 1998: brood mass $=19.54( \pm 32.1 \mathrm{SE})$ $+91.35( \pm 21.7 \mathrm{SE}) \times \mathrm{BL}, r^{2}=0.36, P<0.0002$. (B) Average mass of embryos from clutches differing in size. Average embryo mass decreases significantly with increasing clutch size $(r=-0.71, P<0.0001)$. Open circles represent unpigmented embryos; squares, red-eye stage embryos; solid circles, black-eye stage embryos.
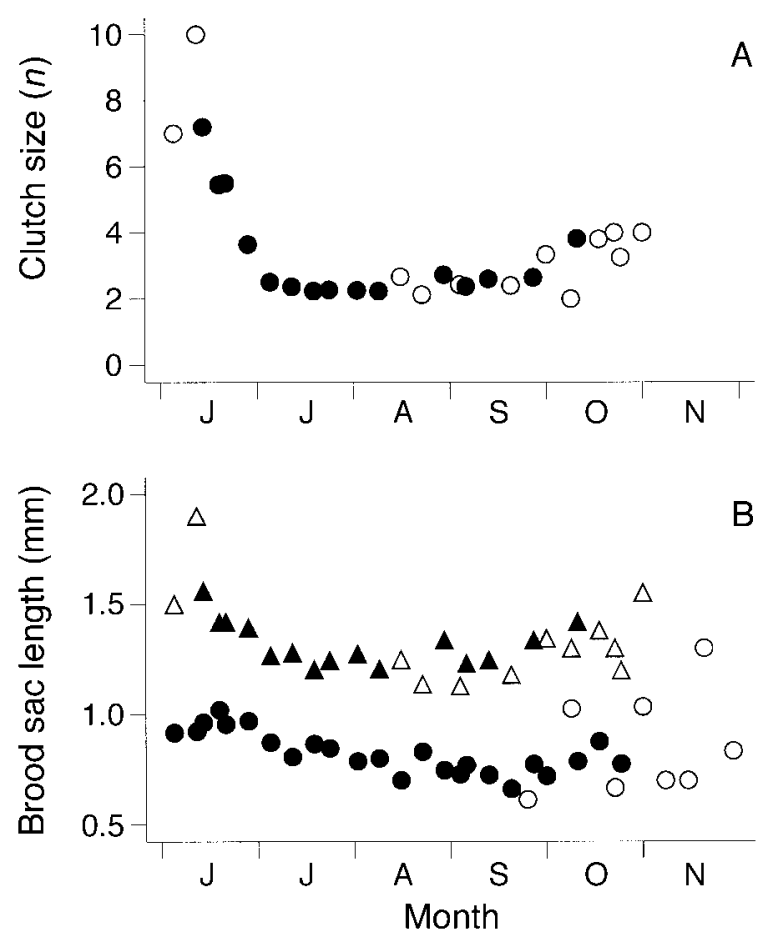

FIG. 7. Seasonal patterns of (A) clutch size and (B) brood sac length (BL). The seasonal pattern of BL is shown for females carrying eggs and nonpigmented embryos (circles), and for females with pigmented embryos (triangles). Open symbols represent observations based on $<10$ individuals; solid symbols represent observations based on $>10$ individuals. was most pronounced for females carrying embryos with pigmented eyes, intermediate for females with eggs and unpigmented-eye embryos, and absent for neonates. An analysis of variance (Table 3 ) revealed significant diel changes in the distribution patterns of the total population (time $\times$ depth interaction: $P<$ $0.0001)$, and significant differences in depth distribution of stages (depth $\times$ stage interaction: $P<0.0001$ ), as well as in stage specific DVM (depth $\times$ time $\times$ stage interaction: $P<0.0001)$.

\section{DISCUSSION}

The environment of zooplankton in temperate lakes is characterized by large seasonal fluctuations. Abundances of a preferred food species for Bythotrephes, i.e., daphnids (Mordukhai-Boltovskaya 1958, Schulz and Yurista 1995), increased by $\sim 3$ orders of magnitude from winter to late spring in Lake Constance. Because of high clutch sizes, increasing water temperatures, and prey abundances, Bythotrephes achieved a high net population increase during June. From midJune until October, Bythotrephes was the dominant diet of adult planktivorous fish (mostly whitefish) in Lake Constance (Becker 1992). Additionally, juvenile perch and whitefish started to ingest Bythotrephes in Lake Constance around July, but in contrast to adult fish, they fed predominantly on smaller cladocerans during their first summer (Hartmann 1983, Wang 1994). However, as young-of-the-year fish normally exceed their older conspecifics strongly in numbers, it is unclear whether it is the juvenile or the adult fish that exert the dominant predation pressure on Bythotrephes in Lake Constance.

Bythotrephes females sampled in June 1998 varied in their reproductive strategies. Some females had high 

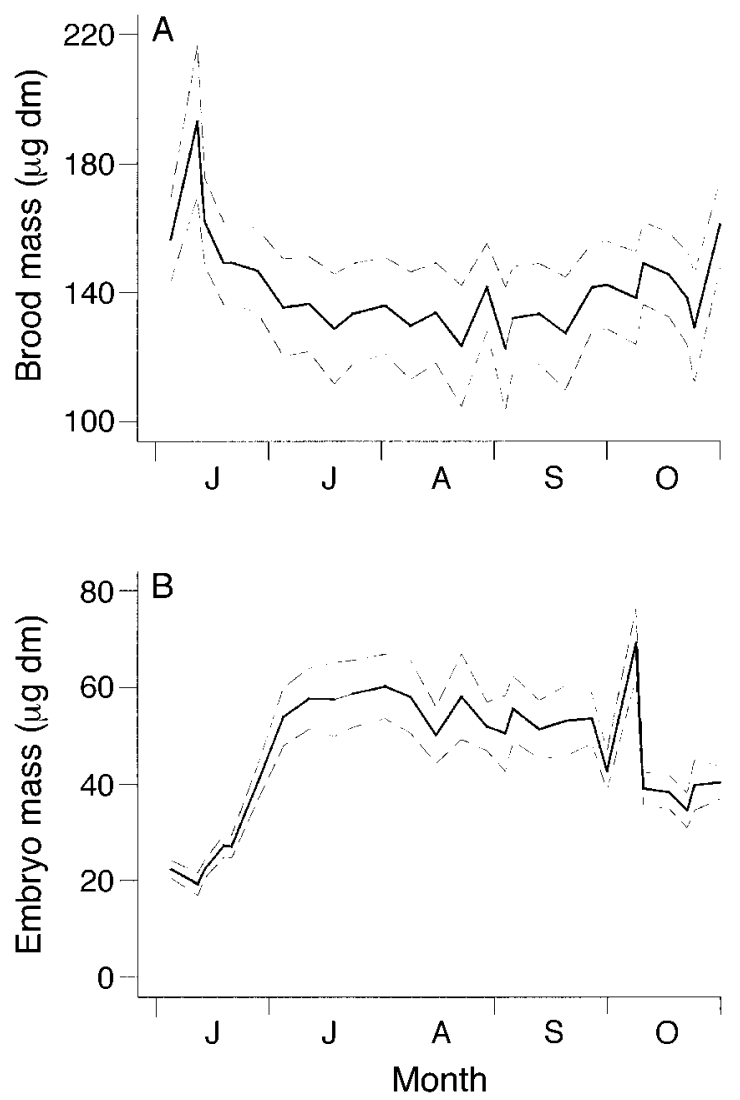

FIG. 8. Predicted seasonal pattern of (A) brood mass (total maternal investment) and (B) embryo mass (per-offspring allocation) of Bythotrephes females. Predictions (mean $\pm 1 \mathrm{SE}$ ) are based on the seasonal patterns of brood pouch length (BL) of females with pigmented embryos and clutch size (see Fig. 7) and the relationship between BL and brood mass (see Fig. 6a).

clutch sizes with low-mass embryos, whereas others had small clutches with embryos weighing on average approximately twice as much as embryos of large clutches. This tradeoff between offspring size and numbers (Smith and Fretwell 1974) is well known in many plant and animal species (Roff 1992). Because BL accounts for these differences in reproductive strategy, it is a more useful predictor of females' reproductive investment than clutch size. Measurements of BL and clutch size suggest a life history shift of the Bythotrephes population during early summer, which is additionally supported by increases in neonate size (Fig. 9a) and size at first reproduction (Fig. 10).

This life history shift seems not to be related to food limitation and predation by adult fish, but is best understood as a response to increasing grazing pressure of juvenile, gape-limited fish. A shift towards the production of large offspring by zooplankton has been observed as a result of food limitation. For instance, Daphnia produced smaller clutches with larger eggs at low food levels compared to high ones (Gliwicz and
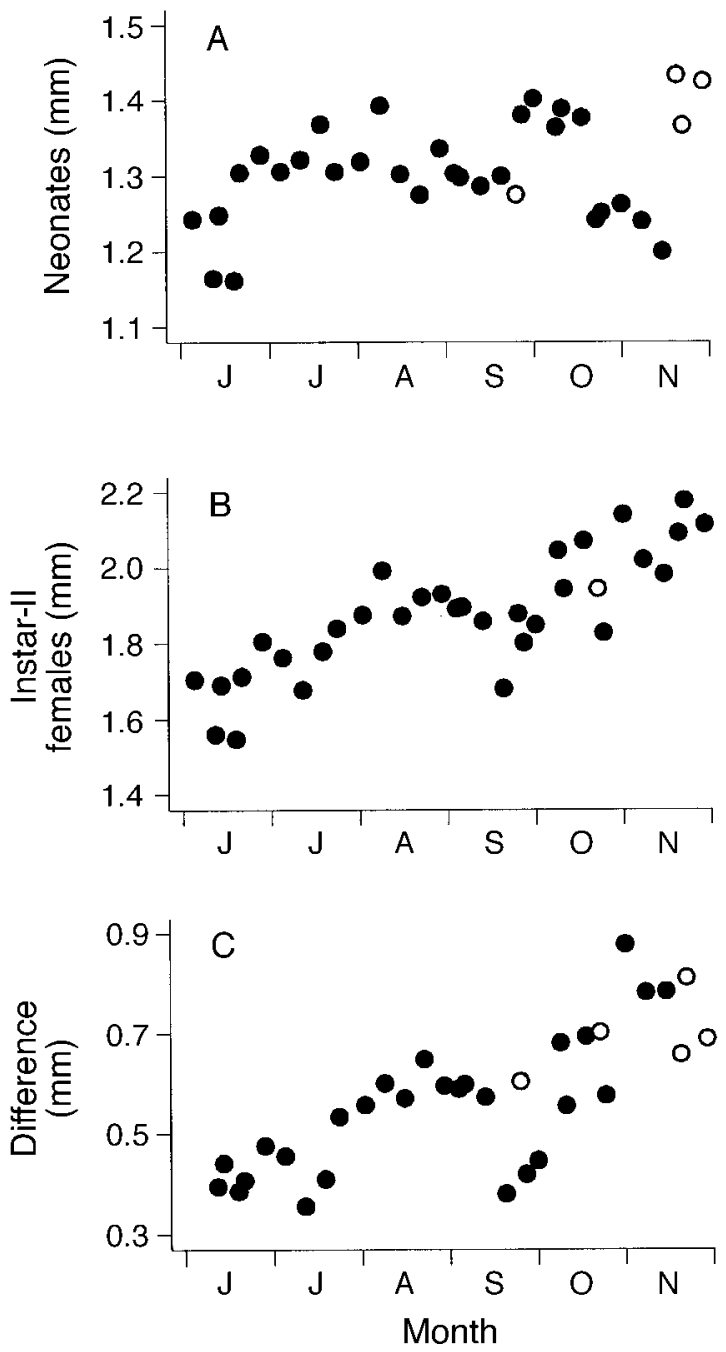

FIG. 9. Seasonal changes in (A) average body size of neonates, (B) average body size of instar-II females, and (C) the difference in body size between the two groups. Open symbols represent observations based on $<10$ individuals; solid symbols represent observations based on $>10$ individuals.

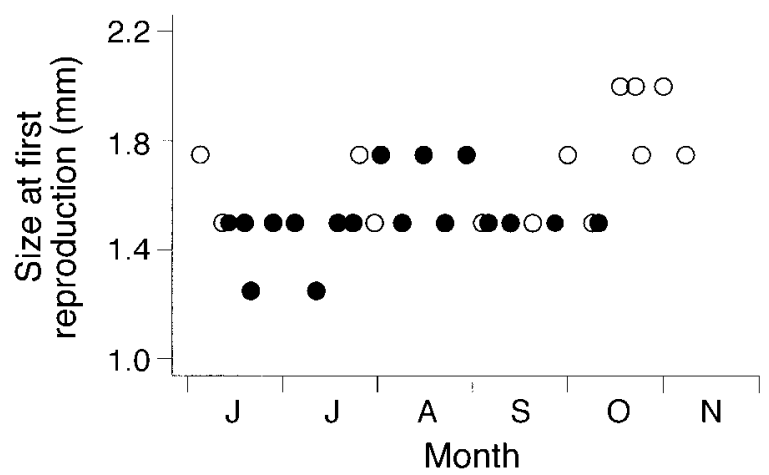

FIG. 10. Size at first reproduction of Bythotrephes females estimated as the size of the smallest female carrying pigmented embryos on the respective sampling dates. Open symbols represent observations based on $<10$ individuals; solid symbols represent observations based on $>10$ individuals. 
TABLE 2. ANCOVA for effects of date, body size, instar, and their interaction on spina length.

\begin{tabular}{lrrrc}
\hline \hline \multicolumn{1}{c}{ Source } & df & Type III ss & \multicolumn{1}{c}{$F$} & $P$ \\
\hline Date & 35 & 23.66 & 5.27 & 0.0001 \\
Body size & 1 & 2.21 & 17.22 & 0.0001 \\
Instar & 2 & 15.18 & 59.09 & 0.0001 \\
Body size $\times$ date & 34 & 29.52 & 6.76 & 0.0001 \\
Instar $\times$ date & 36 & 6.88 & 1.49 & 0.0304 \\
Body size $\times$ instar & 2 & 18.00 & 70.08 & 0.0001 \\
Error degrees of freedom $=5771$ & & \\
Error sum of squares $=741$ & & \\
$r^{2}=0.27$ & & & \\
\hline
\end{tabular}

Guisande 1992). Larger eggs will give birth to larger neonates, which are assumed to be more resistant to food limitation than neonates hatched from smaller eggs (Tessier and Consolatti 1989, Gliwicz and Guisande 1992, Burns 1995). However, as the major life history shift of Bythotrephes in Lake Constance occurred during June, when the biomass of a preferred prey (Daphnia) was still increasing, it was unlikely to be caused by food limitation. Furthermore, production of resting eggs that may indicate scarcity of prey (Yan and Pawson 1998) did not start in reasonable numbers until the end of August (Fig. 4b).

Predation by adult fish, i.e., NGLPs, can also most probably be excluded as a reason for the observed life history shift, because it selects for large clutch size, small offspring size, and small size at first reproduction (Taylor and Gabriel 1992, Vonder Brink and Vanni 1993, Wellborn 1994, Rodd and Reznick 1997). Furthermore, as large planktivorous fish usually select the largest prey items, a shift from producing many small to few large offspring can be considered rather detrimental to the survival of offspring. The life history shift of Bythotrephes matches, however, the response expected in the presence of GLPs (Crowl and Covich 1990, Taylor and Gabriel 1992, Tollrian 1995), in this case, juvenile fish. Larger neonates born also with a large caudal spina could be more resistant to the predation of GLPs.

Plankton ecologists usually distinguish between the effects of vertebrate and invertebrate predators on prey life histories (Lampert and Sommer 1993). For most predator-prey pairs, this taxonomic perspective is also a functional one, in the sense that invertebrate predators of planktonic prey can be considered as size-or gapelimited predators, whereas vertebrate predators, e.g., fish, are NGLPs. Given the predator-prey interaction between juvenile fish and Bythotrephes, the taxonomic classification of predation regimes is misleading. This might explain why previous studies neglected predation pressure of juvenile fish as a potential cause for seasonal changes in, e.g., Bythotrephes' body size, which were observed in Lake Michigan (Burkhardt 1994), Harp Lake (Yan and Pawson 1998), and the Biesbosch Reservoirs (Ketelaars et al. 1995). However, predation by juvenile fish could explain the observed patterns in Lake Constance as well as in other lakes.

The seasonal variability of spina length further suggests that juvenile fish impose an important selection pressure on Bythotrephes. During the period of low predation pressure by GLPs, i.e., before July, the spina is small. As juvenile fish increase in size, they are more likely to consume Bythotrephes (Jachner 1991, Mills et al. 1992, Barnhisel and Harvey 1995, Branstrator and Lehman 1996). The probability of ingestion of Bythotrephes by juvenile yellow perch decreases with increasing spina length (Barnhisel 1991b). Hence, the seasonal increase in spina length may result from increasing predation pressure due to decreasing gape limitation of juvenile fish.

The increase in spina length was partially due to an increase in body size of Bythotrephes, which was expected from a first-order allometric relationship between body size and spina length across Bythotrephes population in Europe (Fig. 14, data from Ischreyt 1930, 1934, 1939). However, spina length increased also independently during the season, indicating increased investment into spina increment. The lack of a relationship between spina length and body size, along with the lack of a difference in spina length between neonates and instar-II females during June and July, contrasts with the allometric relationship and with the on-

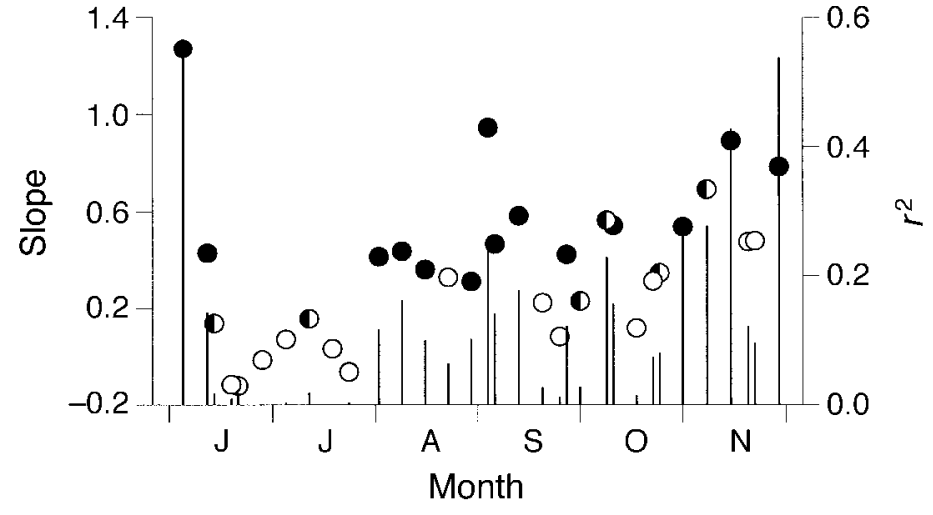

FIG. 11. Seasonal changes in the body-size/ spina-length relationship indicated by the slope (circles; left $y$-axis) and $r^{2}$ (needles; right $y$-axis) of regression models with spina length as the dependent variable are indicated by half-solid circles; slopes and body size as the independent variable. Slopes that differ significantly from zero at $P<0.001$ are indicated by solid circles, and slopes differing significantly from zero at $P<0.05$ as the dependent variable are indicated by half-solid circles; slopes not differing significantly from zero are indicated by open circles. 

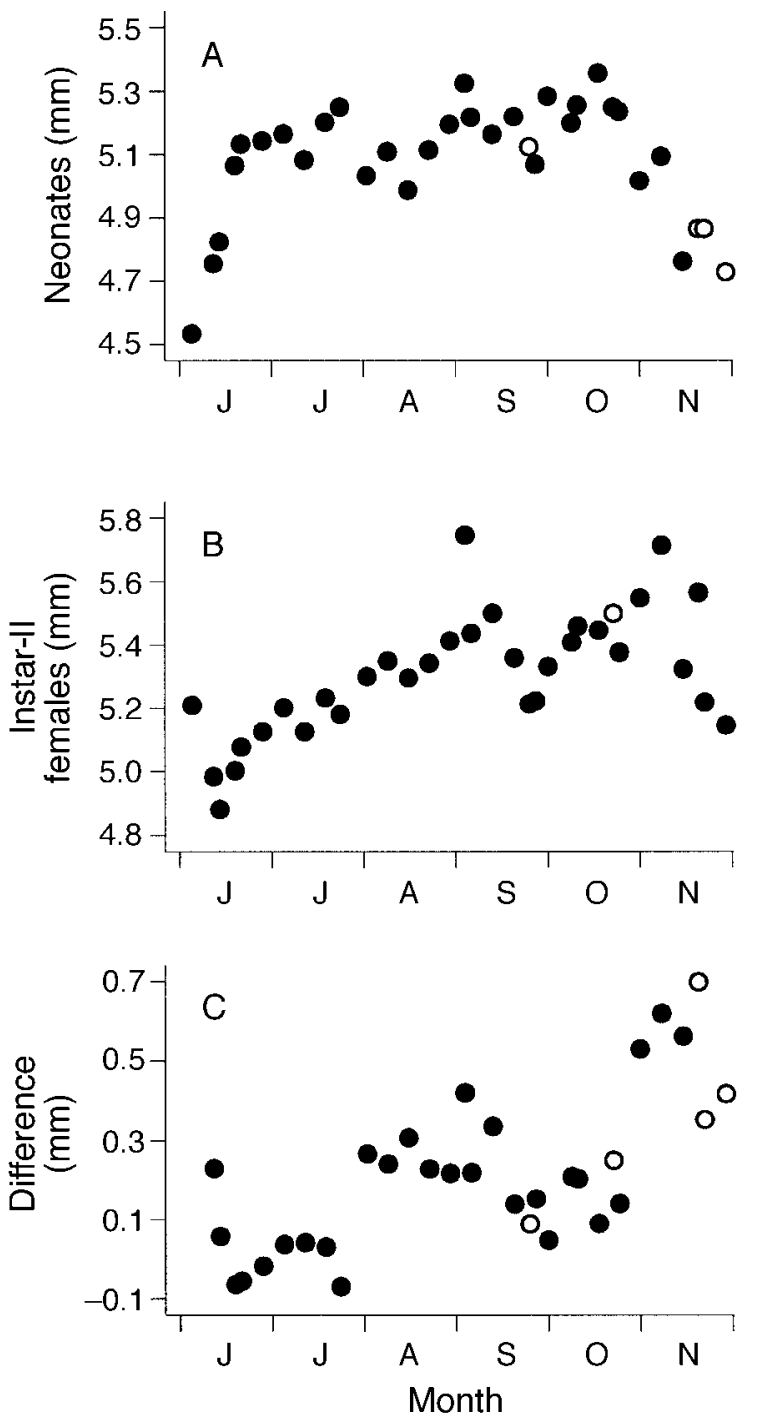

FIG. 12. Seasonal changes in (A) average spina length of neonates, (B) average spina length of instar-II females, and (C) the difference in spina length between the two groups Open symbols represent observations based on $<10$ individuals; solid symbols represent observations based on $>10$ individuals.

togenetic spina growth pattern. Ontogenetic growth of the caudal spine of Bythotrephes occurs between molts, when an additional pair of lateral spines is added (Yurista 1992). Hence, spina length of instar-II females should exceed spina length of neonates. Similar-sized spines of neonates and instar-II females may result when selection pressure changes rapidly within one generation. Instar-II females observed during the end of June and the beginning of July probably belonged to the high clutch size/low embryo weight clutches with small spines from the first part of June. Fecund themselves, they produced low clutch size/high embryo mass clutches with obviously rather large-spined neonates. If, additionally, instar-II females had not in-

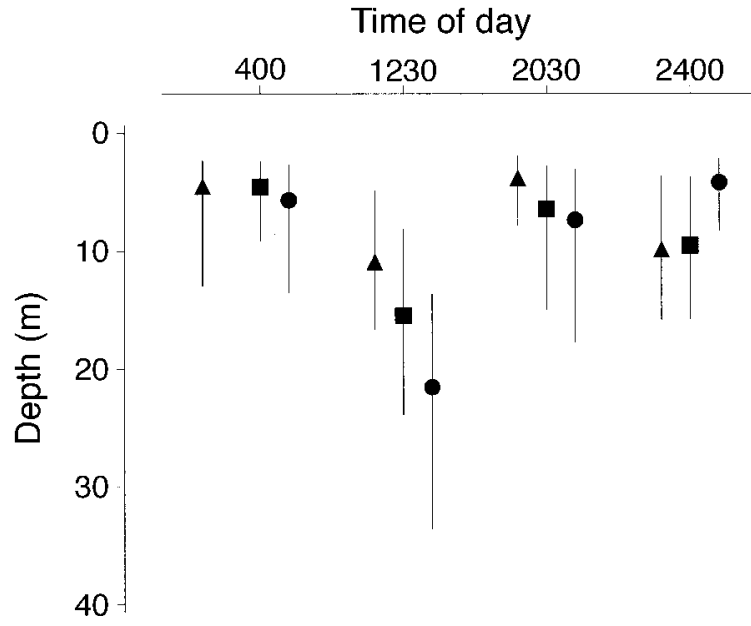

FIG. 13. Depth distribution of neonates (triangles), adults with nonpigmented embryos (squares), and adults with pigmented embryos (circles) shown by quartile depths. Symbols refer to Q-50; lines extend to the interquartil range (Q25Q75)

vested much in spina increment during their first molt, this would have resulted in the lack of a relationship between spina length and body size (Fig. 11) and small differences in spina length between neonates and instar-II females during these months (Fig. 12c).

In contrast to our observations, spina length of $B$. longimanus in the Biesbosch reservoirs was seasonally invariant and small, at $\sim 5 \mathrm{~mm}$, i.e., the average spina length of Bythotrephes in Lake Constance during June, which was attributed to low predation pressure by fish in the Biesbosch reservoirs (Ketelaars et al. 1995). This supports the idea that Bythotrephes does not invest in spina increment when predation pressure is low, which was the case during June in Lake Constance. However,

TABLE 3. Results of a three-way ANOVA on the time-depth distribution of Bythotrephes. The dependent variable is Bythotrephes abundance (no. individuals/L). Independent categorical variables were time, depth, group, and interaction terms.

\begin{tabular}{lrcrc}
\hline \hline \multicolumn{1}{c}{ Source } & df & Type III & & \\
SS & \multicolumn{1}{c}{$F$} & $P$ \\
\hline Time & 3 & 0.00157 & 6.04 & 0.0007 \\
Depth & 5 & 0.05234 & 121.05 & 0.0001 \\
Depth $\times$ time & 15 & 0.01520 & 11.72 & 0.0001 \\
Stage $\times$ stage & 2 & 0.02525 & 145.99 & 0.0001 \\
Time $\times$ stage & 6 & 0.00142 & 2.74 & 0.0148 \\
Depth $\times$ stage $\times$ stage & 10 & 0.01684 & 19.47 & 0.0001 \\
Depth $\times$ time $\times$ sta & 0.01316 & 5.07 & 0.0001
\end{tabular}

Error degrees of freedom $=144$

Error sum of squares $=0.0125$

$r^{2}=0.91$

Notes: Individuals were categorized into three groups: (1) juveniles and adults without brood sac, (2) adults with brood sacs containing eggs or unpigmented embryos, and (3) adults with pigmented embryos. The analysis was based on 216 samples and 2120 individuals. Data were not transformed because $N$ was large and the central limit theorem applies (Kendall and Stuart 1977). 


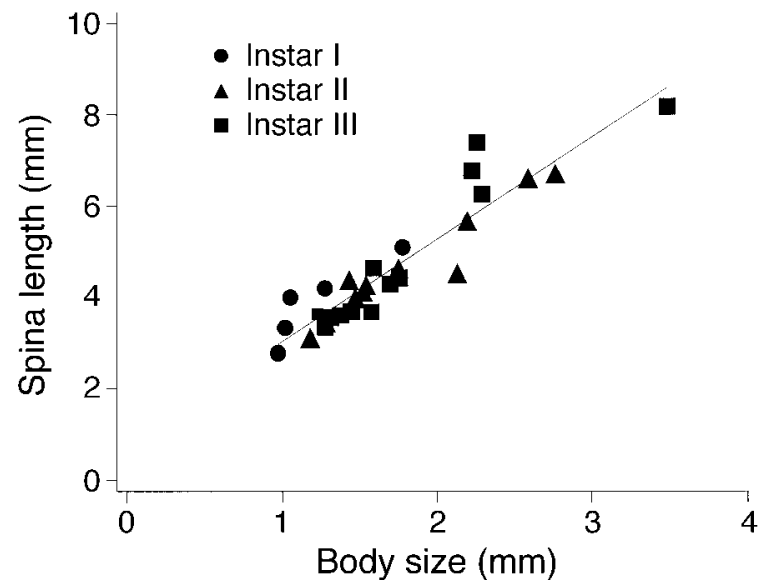

FIG. 14. Relationship between average body size and average spina length within populations of Bythotrephes longimanus and Bythotrephes cederstroemi (spina length $=0.79$ $+2.24 \times$ body size, $\left.r^{2}=0.86, P<0.0001\right)$. Populations were sampled from 19 lakes across Europe, i.e., from northern, eastern, and perialpine Europe in the first half of the 20th century (Ischreyt 1930, 1934, 1939).

increasing predation pressure by juvenile fish probably caused a selection towards larger spined Bythotrephes as the season progressed.

The small migration amplitude of Bythotrephes found in this study and in other lakes (Dokulil et al. 1990, Lampert 1993, Yan and Pawson 1997) does not confirm at first sight to the predator avoidance theory of DVM (Lampert 1993), which predicts large migration amplitudes for large and conspicuous organisms such as Bythotrephes (Lampert 1993, Hays et al. 1994). In contrast, less conspicuous Daphnia hyalina exhibits a DVM in Lake Constance twice the amplitude of $B y$ thotrephes females carrying pigmented embryos and six times the amplitude of the total Bythotrephes population (Einsle 1969, Geller 1986, Stich 1989). The contradiction between current theory and data can be reconciled if the degree of DVM performance of $B y$ thotrephes is viewed as resulting from an interaction between different antipredator defenses, and if juvenile fish are recognized as the dominant planktivorous fish in these lakes. Generally, the amplitude of DVM results from a tradeoff between benefits due to decreased predation rates by fish and costs caused by reduced growth rates in cold hypolimnetic waters (Lampert 1993). If a defensive trait reduces mortality, it will necessarily influence the trade-off associated with other traits (De Meester et al. 1995, Sparkes 1996). Alternative antipredator defenses, such as spina formation and appropriate life history, reduce the mortality of Bythotrephes caused by GLPs and hence reduce the benefits that could be gained through DVM. This should result in a smaller optimum migration amplitude of Bythotrephes compared to daphnids, which are not protected otherwise against juvenile fish.

Migration patterns of different development and/or reproductive stages of Bythotrephes varied according to the predictions of current DVM theory. Larger zooplankton have been repeatedly observed to reside at greater day depths than smaller individuals (Hays et al. 1994, Leibold et al. 1994). The brood sac of Bythotrephes with embryos is almost as large as the body of Bythotrephes itself, and the colored eyes of embryos enhance the conspicuousness of Bythotrephes females further, as was demonstrated also for gravid females of daphnids (Koufopanou and Bell 1984), copepods (Winfield and Townsend 1983), and prawns (Berglund and Rosenquist 1986). Hence, migration behavior of $B y$ thotrephes seems to contradict the predator-avoidance theory at the large scale (overall amplitude was small as compared to other zooplankton species) but is in agreement with theory at the smaller scale; i.e., size specific migration within the overall small migration amplitude varied according to the predictions. This suggests that DVM of gravid females might be understood as a secondary response to the presence of large fish, but would not pay off as a response to juvenile fish, because some protection was already achieved. However, as adult fish were probably less important planktivores than juvenile fish, DVM amplitude of gravid females was modest in comparison to other zooplankton species in Lake Constance.

In the Laurentian Great Lakes (Lehman 1987, Sprules et al. 1990) and inland lakes in the United States and Canada (Yan et al. 1992), adult fish readily recognized the recently invaded $B$. cederstoemi as a preferred prey (Bur and Klarer 1991, Schneeberger 1991, Mills et al. 1992). Nevertheless, B. cederstoemi changed the biomass and size structure of its zooplankton prey (Lehman and Cáceres 1993, Yan and Pawson 1997). Despite its very recent invasion, Bythotrephes already exhibits large morphological variability across lakes; e.g., instar-specific dry masses of the Lake Erie population were $\sim 50 \%$ of those in Lake Huron and Lake Michigan (Garton and Berg 1990, Bilkovic and Lehman 1997), which fits with the results of this study, suggesting that Bythotrephes is able rapidly to respond to changes in, e.g., predation pressure (Bilkovic and Lehman 1997). However, our results also suggest that extreme care has to be taken if Bythotrephes populations from different lakes where compared based on just one or two sampling dates (Garton and Berg 1990, Bilkovic and Lehman 1997). If the large seasonal variability is taken into account, measurements of Bythotrephes body dimensions might be useful indicators for the predation pressure of juvenile fish. As the spina of Bythotrephes is conserved in lake sediments (Keilty 1988, Nilssen and Sandoy 1990, Hall and Yan 1997), it might even be possible to use the information on spina length as a tool to investigate past predation pressures on planktonic communities.

To apply our results to North American Bythotrephes populations, it should be noted that even the small $B$. cederstoemi from Lake Erie is larger than B. longi- 
manus from Lake Constance. The difference in size between $B$. cederstoemi and $B$. longimanus implies that, other things being equal, $B$. cederstoemi might be better protected against GLPs and more vulnerable in respect to NGLPs. This might explain the rather large migration amplitude of $B$. cederstoemi in Lake Michigan (Lehman 1987) and give credence to the suggestion of Bilkovic and Lehman (1997) that the small size of B. cederstoemi in Lake Erie is due to a life history shift in response to NGLPs. However, there is evidence that juveniles of at least two fish species are able to ingest B. cederstoemi in the Great Lakes (Branstator and Lehman 1996). The seasonal increase of B. cederstoemi body size in Lake Michigan (Burkhardt 1994) and Harp Lake (Yan and Pawson 1998) suggests that predation by GLP is an important selective force even for B. cederstoemi populations. A thorough understanding of the defensive traits of Bythotrephes, in respect to both GLPs and NGLPs, will be necessary to predict the further spread and subsequent impact of Bythotrephes on the food webs of North American lakes.

\section{ACKNOWLEDGMENTS}

We thank A. Sulger, the captain of the R.V. Robert Lauterborn, for his help during sampling, and G. Richter for counting daphnid abundance. A. Seifried measured body dimensions and the dry masses of broods in June 1998. W. Nagl provided statistical advice, and Sean Bockover corrected the English. Comments by R. Eckmann, C. Folt, U. Gaedke, K.-O. Rothhaupt, and two anonymous reviewers improved the style and content of this manuscript.

\section{Literature Cited}

Barnhisel, D. R. 1991a. The caudal appendage of the cladoceran Bythotrephes cederstroemi as defence against young fish. Journal of Plankton Research 13:529-537.

Barnhisel, D. R. 1991b. Zooplankton spine induces aversion in small fish predators. Oecologia 88:444-450.

Barnhisel, D. R., and H. A. Harvey. 1995. Size-specific fish avoidance of the spined crustacean Bythotrephes: field support for laboratory predictions. Canadian Journal of Fisheries and Aquatic Science 52:768-775.

Bäuerle, E., and U. Gaedke, editors. 1998. Lake Constance, characterization of an ecosystem in transition. Archiv für Hydrobiologie, Special Issues: Advances in Limnology 53.

Becker, M. 1992. Ingestions-und Selektionsverhalten adulter Felchen (Coregonus lavaretus) des Bodensees: saisonale und diurnale Variabilität. Dissertation, University of Konstanz, Germany.

Berberovic, R., and R. M. Pinto-Coelho. 1989. Dry first, measure later: a new procedure to preserve and measure zooplankton for ecophysiological studies. Journal of Plankton Research 11:1109-1116.

Berg, D. J., and D. W. Garton. 1994. Genetic differentiation in North American and European populations of the cladoceran Bythotrephes. Limnology and Oceanography 39: 1503-1516.

Berglund, A., and G. Rosenquist. 1986. Reproductive costs in the prawn Palaemon adspersus: effects on growth and predator vulnerability. Oikos 46:349-354.

Bilkovic, D. A., and J. T. Lehman. 1997. Lipid concentration and size variation of Bythotrephes (Cladocera: Cercopagidae) from Lakes Erie, Huron, and Michigan. Journal of Great Lakes Research 23:149-159.

Branstrator, D. K., and J. T. Lehman. 1996. Evidence for predation by Young-of-the-year alewife and cloater chub on Bythotrephes cederstroemi in Lake Michigan. Journal of Great Lakes Research 22:917-924.

Brönmark, C., and J. G. Miner. 1992. Predator-induced phenotypic change in body morphology in crucian carp. Science 258:1348-1350.

Brooks, J. L., and S. I. Dodson. 1965. Predation, body size and composition of plankton. Science 150:28-35.

Bur, M. T., and D. M. Klarer. 1991. Prey selection for the exotic cladoceran Bythotrephes cederstroemi by selected Lake Erie fishes. Journal of Great Lakes Research 17:8593.

Burkhardt, S. 1994. Seasonal size variation in the predatory cladoceran Bythotrephes cederstoemi in Lake Michigan. Freshwater Biology 31:97-108.

Burns, C. W. 1995. Effects of crowding and different food levels on growth and reproductive investment of Daphnia. Oecologia 101:234-244.

Crowl, T. A., and A. P. Covich. 1990. Predator-induced lifehistory shifts in a freshwater snail. Science 247:949-951.

De Meester, L., L. J. Weider, and R. Tollrian. 1995. Alternative antipredator defenses and genetic polymorphism in a pelagic predator-prey system. Nature 378:483-485.

Dokulil, M., A. Herzig, and A. Jagsch. 1990. Trophic relationships in the pelagic zone of Mondsee, Austria. Hydrobiologia 191:199-212.

Einsle, U. 1969. Untersuchungen zur Vertikalwanderung planktischer Crustaceen im Bodensee-Obersee. Schriftenreihe des Vereins zur Geschichte des Bodensees 87:177187.

Endler, J. A. 1995. Multiple-trait evolution and environmental gradients in guppies. Trends in Ecology and Evolution 10:22-29.

Fitzmaurice, P. 1979. Selective predation on Cladocera by brown trout Salmo trutta. Journal of Fish Biology 15:521526.

Garton, D. W., and D. J. Berg. 1990. Occurrence of Bythotrephes cederstroemi (Schoedler 1877) in Lake Superior, with evidence of demographic variation within the lakes. Journal of Great Lakes Research 16:148-152.

Geller, W. 1986. Diurnal vertical migration of zooplankton in a temperate great lake (L. Constance): a starvation avoidance mechanism? Archiv für Hydrobiologie/Supplement 74:1-60.

Giussani, G. 1974. Planctofagia selettiva del coregone "Bondella" (Coregonus sp.) del Lago Maggiore. Memorie dell'Istituto Italiano di Idrobiologia 31:181-203.

Gliwicz, Z. M., and C. Guisande. 1992. Family planning in Daphnia: resistance to starvation in offspring born to mothers grown at different food levels. Oecologia 91:463-467.

Hall, R. I., and N. D. Yan. 1997. Comparing annual population growth estimates of the exotic invader Bythotrephes by using sediment and plankton records. Limnology and Oceanography 42:112-120.

Hall, S. J., and D. Raffaelli. 1991. Food-web patterns: lessons from a species-rich web. Journal of Animal Ecology 60:823-842.

Hartmann, J. 1983. Two feeding strategies of young fishes. Archiv für Hydrobiologie 96:496-509.

Harvell, C. D. 1984. Predator-induced defense in a marine bryozoan. Science 224:1357-1359.

Hays, G. C., C. A. Proctor, A. W. G. John, and A. J. Warner. 1994. Interspecific differences in the diel vertical migration of marine copepods: the implications of size, color, and morphology. Limnology and Oceanography 39:1621-1629.

Herzig, A. 1985. Resting eggs - a significant stage in the life cycle of crustaceans Leptodora kindtii and Bythotrephes longimanus. Verhandlungen der Internationalen Vereinigung für Limnologie 22:3088-3098.

Huangh, C., and A. Sih. 1991. An experimental study on the 
effects of salamander larvae on isopods in stream pools. Freshwater Biology 25:451-459.

Ischreyt, G. 1930. Über Körperbau und Lebensweise des Bythotrephes longimanus Leydig. Archiv für Hydrobiologie 21:241-324.

Ischreyt, G. 1934. Über Bythotrephes cederstoemi Schödler. Internationale Revue der gesamten Hydrobiologie und Hydrographie 31:181-202.

Ischreyt, G. 1939. Über den Bythotrephes subalpiner Seen. Archiv für Hydrobiologie 34:105-129.

Jachner, A. 1991. Food and habitat partitioning among juveniles of three fish species in the pelagial of a mesotrophic lake. Hydrobiologia 226:81-89.

Keilty, T. J. 1988. A new biological marker layer in the sediments of the great lakes: Bythotrephes cederstroemi (Schödler) spines. Journal of Great Lakes Research 14 369-371.

Kendall, M. G., and A. Stuart. 1977. The advanced theory of statistics, Vol. 1. Charles Griffin, London, UK.

Ketelaars, H. A. M., A. J. Wagenvoort, R. F. Herbst, P. A. W. van der Salm, and G.-A. J. de Jonge-Pinkster. 1995. Life history characteristics and distribution of Bythotrephes longimanus Leydig (Crustacea, Onychopoda) in the Biesbosch reservoirs. Hydrobiologia 307:239-251.

Koufopanou, V., and G. Bell. 1984. Measuring the cost of reproduction. IV Predation experiments with Daphnia pulex. Oecologia 64:81-86.

Kurzava, L. M., and P. J. Morin. 1998. Tests of functional equivalence: complementary roles of salamanders and fish in community organization. Ecology 79:477-489.

Kvam, O. V., and O. T. Cleiven. 1995. Diel horizontal migration and swarm formation in Daphnia in response to Chaoborus. Hydrobiologia 307:177-184.

Lampert, W. 1993. Ultimate causes of diel vertical migration of zooplankton: New evidence for the predator-avoidance hypothesis. Archiv für Hydrobiologie Beiheft. Ergebnisse der Limnologie 39:79-88.

Lampert, W., and U. Sommer. 1993. Limnoökologie. Georg Thieme Verlag, Stuttgart, Germany.

Langeland, A. 1978. Effect of fish (Salvelinus alpinus, arctic charr) predation on the zooplankton in ten Norwegian lakes. Verhandlungen der Internationalen Vereinigung für Limnologie 20:2065-2069.

Lehman, J. T. 1987. Paleartic predator invades North American Great Lakes. Oecologia 74:478-480.

Lehman, J. T., and C. E. Cáceres. 1993. Food-web responses to species invasion by a predatory invertebrate: Bythotrephes in Lake Michigan. Limnology and Oceanography 38 879-891.

Leibold, M. A., Tessier, A. J., and C. West. 1994. Genetic, acclimatization and ontogenetic effects on habitat selection in Daphnia pulicaria. Evolution 48:1324-1332.

Lima, S. L., and L. M. Dill. 1990. Behavioral decisions made under risk of predation: a review and prospectus. Canadian Journal of Zoology 68:619-640.

Mehner, T., and I. Winfield. 1997. editors. Trophic interactions of age-0-fish and zooplankton in temperate waters. Archiv für Hydrobiologie, Advances in Limnology 49: $1-149$.

Mills, E. L., R. O'Gorman, J. DeGisi, R. F. Heberger, and R. A. House. 1992. Food of the alewife (Alosa pseudohar engus) in Lake Ontario before and after the establishment of Bythotrephes cederstroemi. Canadian Journal of Fisheries and Aquatic Science 49:2009-2019.

Mordukhai-Boltovskaya, E. D. 1957. Parthenogenic breeding of Leptodora kindtii (Focke) and Bythotrephes (Leydig). Academia Nauk SSSR Doklady 112:1133-1135.

Mordukhai-Boltovskaya, E. D. 1958. Preliminary notes on the feeding of the carnivorous cladocerans Leptodora kindtii and Bythotrephes. Academia Nauk SSSR Doklady 122:828-830.
Nilssen, J. P., and S. Sandoy. 1990. Recent lake acidification and cladoceran dynamics: surface sediment and core analysis form lakes in Norway, Scotland and Sweden. Philosophical Transactions of the Royal Society of London, Series B 327:299-310.

Nilsson, N.-A. 1974. Food relationship of the fish community in the offshore region of Lake Vänern. Institute of Freshwater Research Drottningholm, Report 17:1-57.

Persson, L., J. Andersson, E. Wahlström, and P. Eklöv. 1996. Size-specific interactions in lake systems: predator gape limitation and prey growth rate and mortality. Ecology 77: 900-911.

Polis, G. A. 1988. Exploitation, competition, and the evolution of interference, cannibalism, and intraguild predation ine age/size-structured populations. Pages 185-202 in B. Ebenman and L. Persson, editors. Size-structured populations, ecology and evolution. Springer Verlag, Berlin, Germany.

Polis, G. A. 1991. Complex trophic interactions in deserts: an empirical critique of food-web theory. American Naturalist 138:123-155.

Rodd, F. H., and D. N. Reznick. 1997. Variation in the demography of Guppy populations: the importance of predation and life histories. Ecology 78:405-418.

Roff, D. A. 1992. The evolution of life histories. Chapman \& Hall, New York, New York, USA.

SAS Institute. 1988. SAS/STAT user's guide, release 6.03 edition. SAS Institute, Cary, North Carolina, USA.

Schneeberger, P. J. 1991. Seasonal incidence of Bythotrephes cederstroemi in the diet of yellow perch (ages $0-4)$ in little Bay de Noc, Lake Michigan 1988. Journal of Great Lakes Research 17:281-285.

Schulz, K. L., and P. M. Yurista. 1995. Diet composition from allozyme analysis in the predatory cladoceran Bythotrephes cederstroemi. Limnology and Oceanography 40: 821-826.

Sih, A. 1994. Predation risk and the evolutionary ecology of reproductive behaviour. Journal of fish biology 45:111130.

Sih, A., G. Englund, and D. Wooster. 1998. Emergent impacts of multiple predators on prey. Trends in Ecology and Evolution 13:350-355.

Smith, C. C., and S. D. Fretwell. 1974. The optimal balance between size and number of offspring. American Naturalist 108:499-506.

Sparkes, T. C. 1996. The effects of size-dependent predation risk on the interaction between behavioral and life history traits in a stream-dwelling isopod. Behavioral Ecology and Sociobiology 39:411-417.

Sprules, W. G., H. P. Riessen, and E. H. Jin. 1990. Dynamics of the Bythotrephes invasion of the St. Lawrence Great Lakes. Journal of Great Lakes Research 16:346-351.

Stemberger, R. S., and J. J. Gilbert. 1987. Multiple species induction of morphological defense in the rotifer, Keratella testudo. Ecology 68:370-378.

Stich, B.-B. 1989. Seasonal changes of diel vertical migrations of crustacean zooplankton in Lake Constance. Archiv für Hydrobiologie/Supplement 83:355-405.

Straile, D., and W. Geller. 1998. Crustacean zooplankton in Lake Constance from 1920 to 1995: response to eutrophication and re-oligotrophication. Archiv für Hydrobiologie, Special Issues: Advances in Limnology 53:255-274.

Swaffar, S. M., and W. J. O'Brien. 1996. Spines of Daphnia lumholtzi create feeding difficulties for juvenile bluegill sunfish (Lepomis macrochirus). Journal of Plankton Research 18:1055-1061.

Taylor, B. E., and W. Gabriel. 1992. To grow or not to grow: optimal resource allocation for Daphnia. American Naturalist 139:248-266.

Tessier, A. J., and N. L. Consolatti. 1989. Variation in off- 
spring size in Daphnia and consequences for individual fitness. Oikos 56:269-276.

Tollrian, R. 1995. Predator-induced morphological defenses: costs, life history shifts, and maternal effects in Daphnia pulex. Ecology 76:1691-1705.

Vonder Brink, R. H., and M. J. Vanni. 1993. Demographic and life history response of the cladoceran Bosmina longirostris to variation in predator abundance. Oecologia 95: 70-80.

Wang, N. 1994. On the ecology of Age-0-Perch (Perca fluviatilis L.) in Lake Constance. Ph.D. Thesis, University of Konstanz. Hartung-Gorre Verlag, Konstanz, Germany.

Wellborn, G. A. 1994. Size-biased predation and prey life histories: a comparative study of freshwater amphipod populations. Ecology 75:2104-2117.

Wicklow, B. J. 1988. Developmental polymorphism induced by intraspecific predation in the ciliated protozoan Onynchodromus quadricornotus. Journal of Protozoology 35 137-141.

Wilbur, H. M. 1988. Interactions between growing predators and growing prey. Pages 157-172 in B. Ebenman and L.
Persson, editors. Size-structured populations, ecology and evolution. Springer Verlag, Berlin, Germany.

Wilbur, H. M., and J. E. Fauth. 1990. Experimental aquatic food webs: interactions between two predators and two prey. American Naturalist 135:176-204.

Winfield, I. J., and C. R. Townsend. 1983. The cost of reproduction: increased susceptibility to fish predation. Oecologia 60:407-411.

Yan, N. D., W. I. Dunlop, T. W. Pawson, and L. E. MacKay. 1992. Bythotrephes cederstroemi (Schoedler) in Muskoka lakes: first records of the European invader in inland lakes in Canada. Canadian Journal of Fisheries and Aquatic Science 49:422-426.

Yan, N. D., and T. W. Pawson. 1997. Changes in the crustacean zooplankton community of Harp Lake, Canada, following invasion by Bythotrephes cederstroemi. Freshwater Biology 37:409-426.

Yan, N. D., and T. W. Pawson. 1998. Seasonal variation in the size and abundance of the invading Bythotrephes in Harp Lake, Ontario, Canada. Hydrobiologia 361:157-168. Yurista, P. M. 1992. Embryonic and postembryonic development in Bythotrephes cederstoemi. Canadian Journal of Fisheries and Aquatic Science 49:1118-1125. 